\title{
Computer-assisted implant placement and full-arch immediate loading with digitally prefabricated provisional prostheses without cast: a prospective pilot cohort study
}

Nikolay Makarov ${ }^{1 *}$ D, Giorgio Pompa ${ }^{2}$ and Piero Papi ${ }^{1}$

\begin{abstract}
Background: Immediate loading of implant-supported full-arch rehabilitations has become routine practice when treating edentulous patients. The combination of static computer-aided implant surgery (s-CAIS) and digital prosthetic workflow could eliminate several treatment steps and facilitate prostheses delivery.

The aim of this study is to evaluate the 1-year results of digitally prefabricated polymethyl methacrylate (PMMA) provisional prostheses without a cast for full-arch computer-assisted immediate loading.

Materials and methods: A digital pre-operative treatment planning was realized for all patients: dental implants and screw-retained abutments were selected in the planning software and two surgical templates were fabricated for each patient. The first template was mucosa or teeth-supported to drill the holes for fixating pins, while the second template was placed after raising a full-thickness flap and was supported by pins as well as soft or hard tissue distal support. Furthermore, based on the surgical planning, interim prostheses were digitally designed and milled of PMMA resin blocks with subsequent pink resin veneering. Osteotomies and implant placement were performed through the surgical guides and all implants were immediately loaded with prefabricated full-arch interim prostheses directly connected to titanium copings with a flowable resin.

Results: A total of 55 dental implants were placed in ten patients. In all cases, interim prostheses allowed the insertion of titanium copings without the need of access hole enlargement or adaptation. All the prostheses had 1 year of functional loading to simulate the long provisional phase. No screw loosening occurred at the first removal of the prostheses after implant osseointegration. No fracture occurred during the whole period. After 1 year, the mean marginal bone loss level was $0.37 \pm 0.06 \mathrm{~mm}$, while the implant survival rate was $98.18 \%(n=54 / 55)$, with just one implant failing but not affecting final prosthesis delivery to the patient.
\end{abstract}

\footnotetext{
* Correspondence: nikolay.makarov@ymail.com

'Department of Oral and Maxillo-Facial Sciences, "Sapienza" University of

Rome, Via Caserta, 6, 00161 Rome, Italy

Full list of author information is available at the end of the article
}

\section{Springer Open}

( ) The Author(s). 2021 Open Access This article is licensed under a Creative Commons Attribution 4.0 International License, which permits use, sharing, adaptation, distribution and reproduction in any medium or format, as long as you give appropriate credit to the original author(s) and the source, provide a link to the Creative Commons licence, and indicate if changes were made. The images or other third party material in this article are included in the article's Creative Commons licence, unless indicated otherwise in a credit line to the material. If material is not included in the article's Creative Commons licence and your intended use is not permitted by statutory regulation or exceeds the permitted use, you will need to obtain permission directly from the copyright holder. To view a copy of this licence, visit http://creativecommons.org/licenses/by/4.0/. 
Conclusions: Within the limitations of the present study, the authors concluded that digitally prefabricated provisional prostheses for full-arch immediate loading with s-CAIS could be a valid alternative treatment modality. Milled PMMA restorations proved to be durable enough during the long provisional phase, without prosthetic complications.

Keywords: CAD-CAM, Surgery, Computer-Assisted, Immediate dental implant loading, Dental implants, Printing, Three-Dimensional

\section{Background}

Nowadays, immediate loading of implant-supported fullarch rehabilitation has become a routine practice when treating edentulous patients, giving comparable results to conventional and early loading protocols, improving patient acceptance and comfort $[1,2]$. The conventional procedure includes freehand implant placement, impression taking, and prosthesis delivery within 1 week after surgery [3]. However, this time frame might be too long for either the dentist or the patient. According to recent articles, static computer-aided surgery (s-CAIS) has shown an acceptable level of accuracy [4-7]. However, interim prostheses production process might be affected by working cast and impression contraction and deformation [8]. There are several options to deliver an interim prosthesis: the conversion of a pre-existent complete denture $[9,10]$ or the fabrication of a new prosthesis. According to Lin et al. [11], the most common complications associated with an interim full-arch fixed acrylic resin prosthesis are the fracture of the prosthetic structure and fracture of the veneering material, while based on Crespi et al.'s [12] results, immediate restorations had the same clinical outcome regardless of whether they were reinforced with a metal framework. Furthermore, a greater fracture rate has been reported when converting an existing denture, due to the lack of strength caused by the creation of the access holes [13, 14]. Digital workflow could eliminate several treatment steps, such as impression taking, reducing the risk of fracture, and the need for a reinforcement of the interim prostheses, due to the use of more durable CAD/CAM materials, such as milled polymethyl methacrylate (PMMA) [15, 16]. Just a few studies have documented prosthesis fabrication before implant surgery [17-20]. In the present article, the authors would like to discuss an alternative digital workflow for implant-supported fullarch rehabilitations. The aims of this study are to evaluate the 1-year results of digitally prefabricated PMMA provisional prostheses for full-arch computer-assisted immediate loading.

\section{Materials and methods}

To address the research purpose, the authors designed and implemented this prospective pilot cohort study, conducted at the University clinic and approved by the local Institution Review Board of the Department of Oral and Maxillo-Facial Sciences at "Sapienza" University of Rome. The study sample was composed by patients presenting at the university department for implant treatment of complete edentulism. In order to be included in the study, patients had to meet the following inclusion and exclusion criteria: fully edentulous jaws or failing dentitions, good oral hygiene (FMPS and FMBS $<25 \%$ ), absence of uncontrolled systemic diseases, non-smokers $(<10$ cigarettes/day), non-pregnancy or lactation, and no signs of local inflammation. All patients included signed the informed consent forms according to the latest edition of the World Medical Association's Declaration of Helsinki and declared their commitment to participate for the full duration of the study.

At the first visit, each patient performed a panoramic radiograph to conduct initial treatment planning. All patients included in the study received new dentures with the intended occlusal vertical dimension, prepared using four teeth made of radiopaque resin to serve also as a radiographic template. The dentures were further relined before the acquisition of the cone-beam computer tomography (CBCT) scan for a precise transition of the actual soft tissue of the patient in the CAD (computeraided design). A dual-scanning protocol was, then, implemented: a CBCT scan was performed at the patient wearing the radiographic template (Fig. 1) and separately at the radiographic template alone, in order to

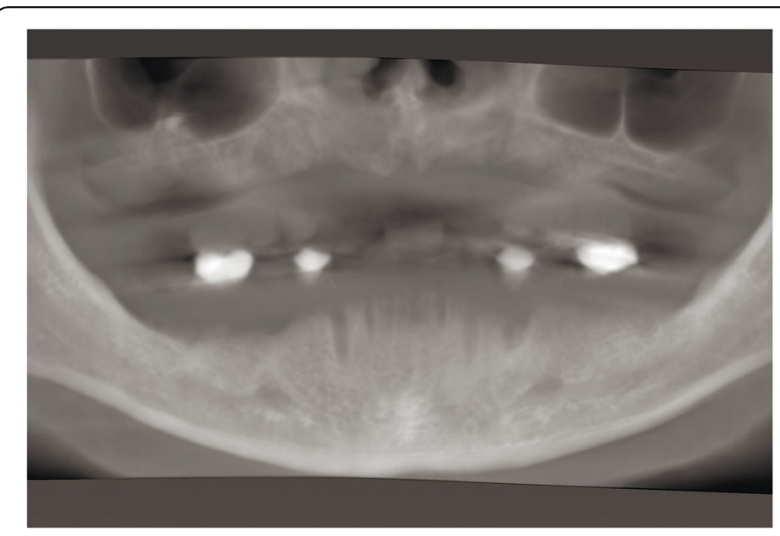

Fig. 1 Pre-operative $C B C T$ with radiographic template and radiopaque teeth 
prosthetically orient implant positions and create a surgical template for computer-assisted implant placement. Conventional impressions of the radiographic template and the opposing arch were made with polyvinyl siloxane (Elite, Zhermack); furthermore, an intraoral occlusion index was recorded (Occlufast; Zhermack). Working casts (Type IV dental stone, Ultrarock) were poured and scanned by means of a laboratory scanner (7 Series; Dental Wings) to obtain STL (Standard Tessellation Language) files. CBCT data of the patients in DICOM (Digital Imaging and Communications in Medicine) format, STL and DICOM files of the radiographic templates were inserted and matched in a surgical planning software (coDiagnostiX, Dental Wings). All acquired data in STL format were superimposed, the implants and $4.6 \mathrm{~mm}$ diameter screw-retained abutments (SRA) were planned in prosthetically oriented positions (Fig. 2), and surgical templates with lateral fixation pin support and retention were designed for guided implant placement (Figs. 3 and 4). Surgical templates were then exported as STL files and 3D-printed (Straumann P 30+, Institut Straumann AG) (Figs. 5 and 6). The connection was established between dentists' and dental technicians' software with the "Synergy" function implemented in both software, which allowed them to work on the same patient in their software and introduce minor changes to the planning. The planning in surgical software was matched with the dental laboratory software Cares Visual (Institut Straumann AG) through CaseXchange data transfer channel. The dental technician designed the interim prostheses in accordance with the anatomy obtained by the STL files (Fig. 7); in all cases, the cantilever lengths were inferior to $15 \mathrm{~mm}$ [21]. The access holes were designed considering the planned SRA positions and the connectors of the prostheses were designed to be positioned with the same pins of the surgical templates. The prostheses were milled of PMMA-based resin blocks with subsequent pink resin veneering (Fig.

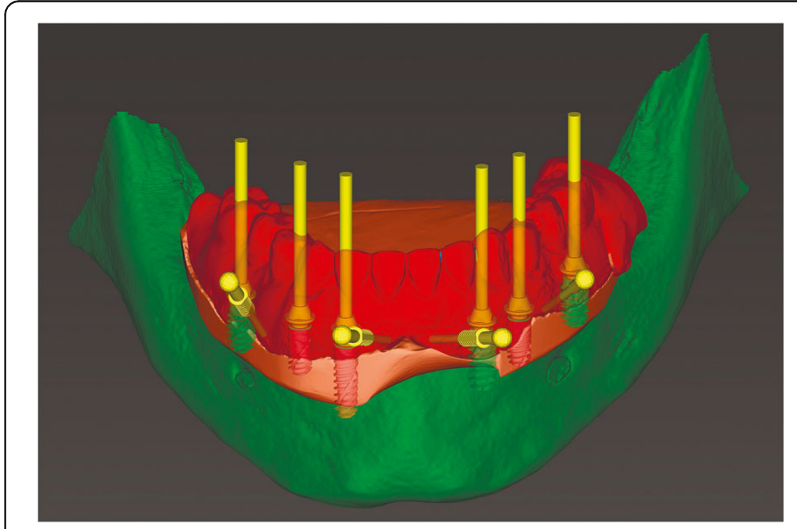

Fig. 2 Matching DICOM and STL files, prosthetically driven implant surgical planning



Fig. 3 Computer-aided design of surgical templates for fixating pins

8) in a production facility (Createch). The basal surface of the prostheses was fabricated with an ovate shape, and a close contact with the mucosa was avoided to ensure cleanability. In none of the patients, there was a need to make a cast during prostheses fabrication. One hour before surgery, prophylactic antibiotics were given to patients: $2 \mathrm{~g}$ of amoxicillin (Zimox, Pfizer) or, in case of allergy, $500 \mathrm{mg}$ of azithromycin (Zitromax, Pfizer). The protocol involved the use of two surgical templates: the first was mucosa or teeth-supported to drill the holes for fixation pins (Fig. 9); the second template was placed after raising a full-thickness flap and was supported by pins and soft or hard tissue distal support. When needed, minor bone reduction was performed. Osteotomies (Fig. 10) and implant placement (Fig. 11) were performed through the surgical template, and then tapered dental implants (BLX or BLT) with a sandblasted/longgrit/acid-etched active (SLActive) surface were inserted following proper manufacturers' instructions and the surgical insertion protocol (Institut Straumann AG). Immediate loading was performed only when dental implants reached a minimum insertion torque of $35 \mathrm{Ncm}$.

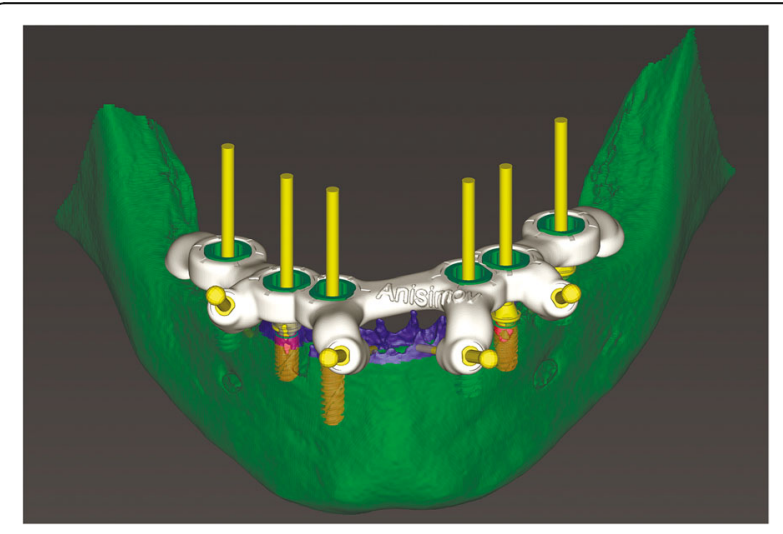

Fig. 4 Computer-aided design of surgical templates for implant placement 


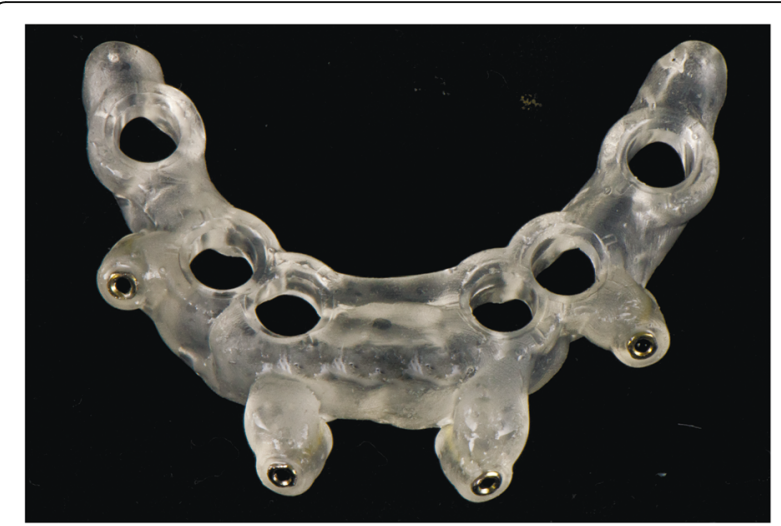

Fig. 5 Computer-aided manufacturing of surgical templates for fixating pins

The SRA previously selected in the surgical planning software were tightened to the implants at $35 \mathrm{Ncm}$ (Fig. 12) with a surgical motor with torque control (Implantmed, W\&H). Interim titanium copings were, then, screwed on SRA abutments (Fig. 13) and the prefabricated prostheses were positioned using the same pins of the surgical guides (Fig. 14) and directly connected to titanium copings by means of an autopolymerizing resin (Acrytemp, Zhermack). The prostheses were, then, unscrewed and the flaps sutured with nonabsorbable sutures (5.0 Prolene). Prostheses were polished, the connectors to the pins were removed, and they were delivered to the patients after occlusion checking, tightening the screws at $15 \mathrm{Ncm}$ and sealing the screw access holes with a polytetrafluoroethylene (PTFE) tape and a flowable composite resin. A panoramic radiograph was taken immediately after implant placement (Fig. 15). Patients left the clinic with the interim fixed prostheses the same day of surgery.

Patients were instructed to rinse twice a day with an antiseptic mouthwash with chlorhexidine $0.2 \%$

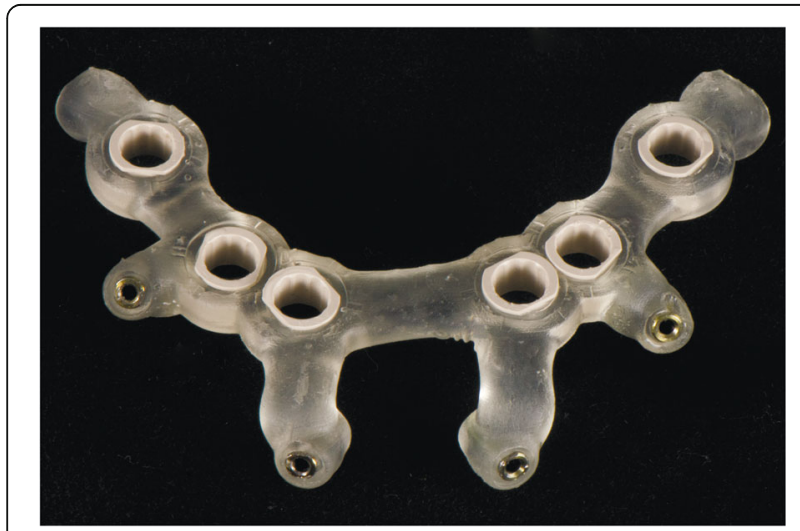

Fig. 6 Computer-aided manufacturing of surgical templates for implant placement

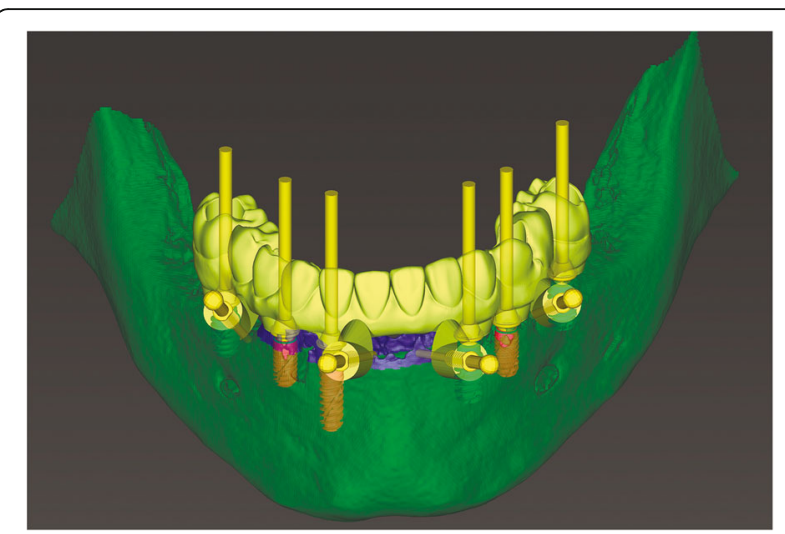

Fig. 7 Computer-aided design of interim prosthesis

(Curasept, Curaden Healthcare S.p.A) for $60 \mathrm{~s}$ starting for 10 days and to avoid tooth brushing for the first 2 weeks of healing. Furthermore, a soft diet was recommended, and ibuprofen $600 \mathrm{mg}$ (Brufen, Abbott) was prescribed to be taken as needed. Medical check-ups were scheduled at 1 week and sutures were removed after 14 days. Then, patients were instructed to restart mechanical cleaning of the prosthetic surfaces and to use interdental brushes of different dimensions to clean the implant neck area and the apical component of the prostheses as proposed by Corbella et al. [22].

At the following appointments $(1,3,6$, and 12 months), specific oral hygiene instructions were given to patients, adapting interdental brush dimensions to the width of the gap between the mucosa and the prostheses due to soft tissue healing. The prostheses were firstly removed at the 3-month check-up to verify implants' osseointegration. An implant in place at the end of the follow-up period was considered as a surviving implant.

A prosthesis in place at the end of the follow-up period was considered as a surviving prosthesis.

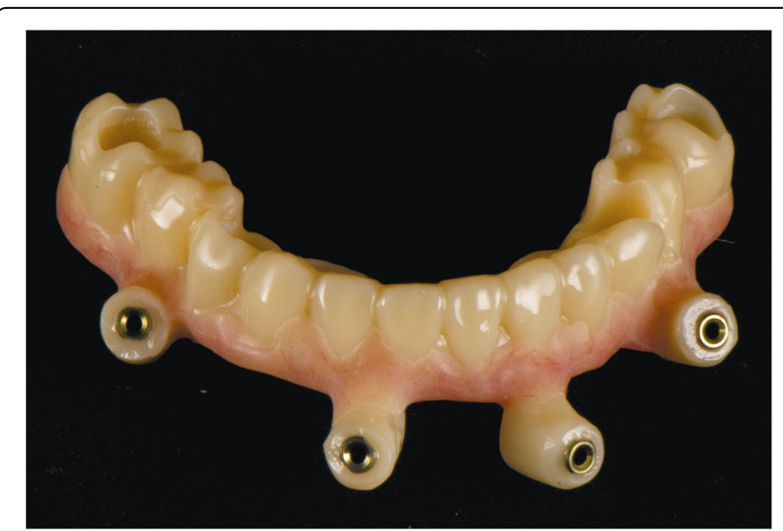

Fig. 8 Computer-aided manufacturing of interim prosthesis with holes 




Fig. 9 Template for fixating pins

Prosthetic success was defined as a prosthesis that is stable and in good function and with the following characteristics: absence of abutment mobility, no implementation of corrective measures, or reparations to either prosthesis or abutment.

The following data were collected for each patient included in the study: number and position of dental implants, implant length and diameter, and opposing dentition (natural teeth, complete conventional denture, removable partial denture).

A specific analysis software (SOPRO Imaging, Acteon Group) was used to evaluate mean MBL levels on digital periapical X-rays acquired through an imaging plate scanner $\left(\right.$ PSPIX $^{2 \oplus}$, Acteon Group, Norwich, UK) and taken by means of the parallel cone technique using a Rinn alignment system (XCP Centratore, Rinn, York, PA, USA). The bone level was digitally assessed for each implant mesially and distally by calculating the distance between the implant shoulder and the first visible bone contact. The implant length and width were used as references for calibration of measurements by two independent

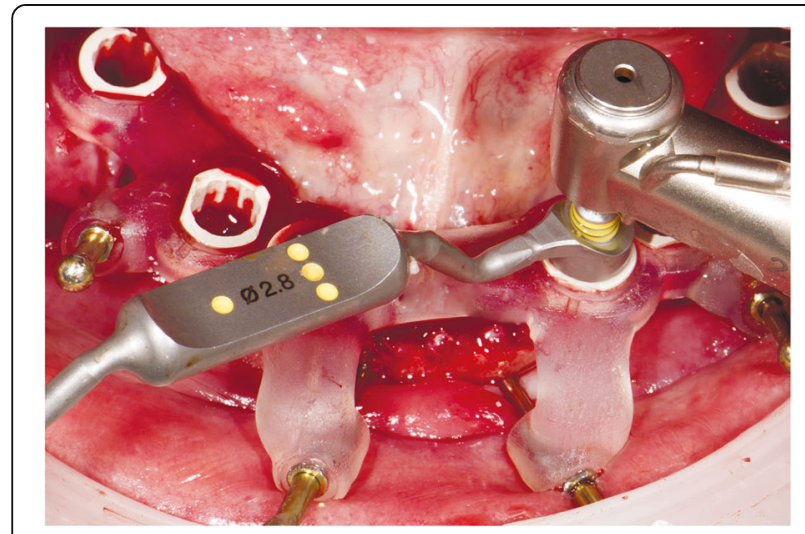

Fig. 10 Implant osteotomies performed through a surgical template

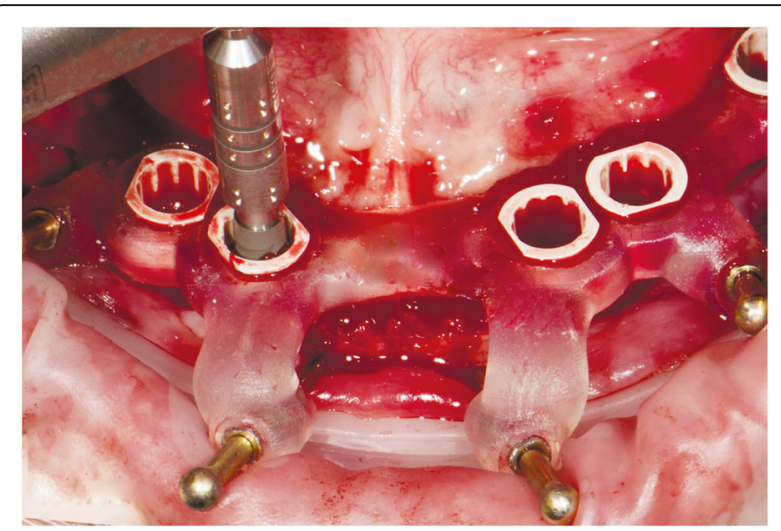

Fig. 11 Guided implant placement

examiners who conducted the assessment. Measurements were taken after 1 year (Fig. 16).

A database was created with Excel (Microsoft). Descriptive statistics including mean \pm SD values and percentage were calculated for each variable.

\section{Results}

A total of ten patients were included in the study; they were either males (6) or females (4), with a mean age of $63.71 \pm 14.55$ years (range $=33-77$ years). Eight patients were fully edentulous and were treated with conventional implant placement and immediate loading. Two patients were partially edentulous and underwent immediate implant placement: one of them had two teeth serving as attachments to a complete overdenture, the other patient had only one tooth to retain a removable partial denture.

A total of 55 dental implants (Table 1) and SRA (Table 2) were placed in ten patients by NM and PP.

Seven patients received six Straumann BLX SLActive (Institut Straumann AG) implants in the mandible with straight SRA. As opposing dentition, four of them had

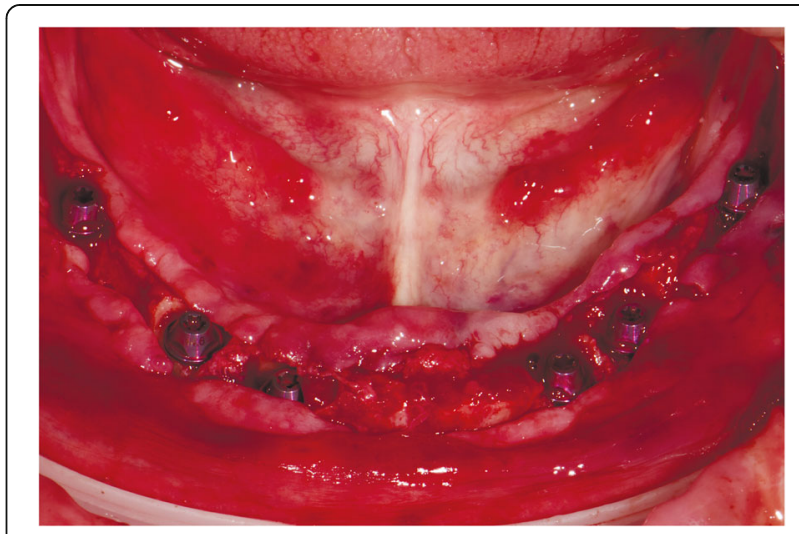

Fig. 12 Screw-retained abutments fixation on implants 




Fig. 13 Interim titanium copings in situ fixed on screw-retained abutments

conventional complete denture, while two patients presented fixed dental prostheses supported by natural teeth and one patient had a removable partial denture as the antagonist. Two patients received four BLX implants in the mandible with two distal implants tilted with $17^{\circ}$ angulated SRA in one patient and two distal implants tilted with $30^{\circ}$ angulated SRA in the other patient. One of these patients had a conventional complete denture as an antagonist, the other had a fixed implant-supported prosthesis. One patient received five Straumann BLT SLActive (Institut Straumann AG) implants in the maxilla with two distal implants tilted with $30^{\circ}$ angulated SRA, one distal implant with $17^{\circ}$ angulated SRA, and two front implants placed axially with straight SRA. The patient had a removable partial denture as an opposing arch. No adverse reactions or wound healing complications were reported after implant placement. All the prostheses had 1 year of functional loading to simulate the long provisional phase (Fig. 17), with a prostheses survival rate of $100 \%$ and success rate of $70 \%$. No screw loosening occurred at the third-month appointment. No



Fig. 14 Interim prosthesis positioned and fixed with the same pins of the surgical guides

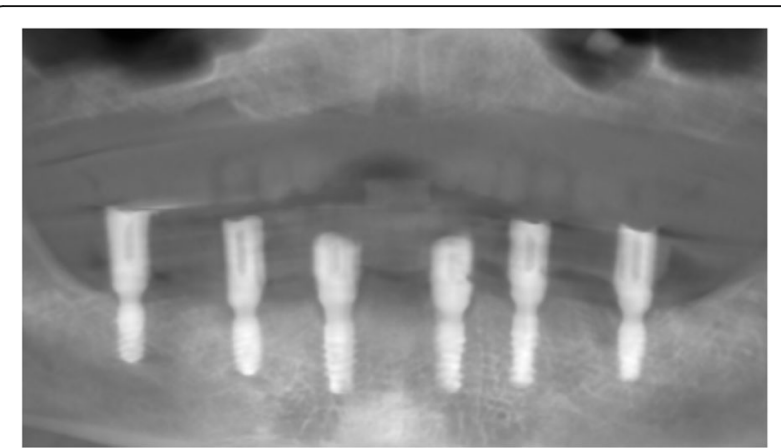

Fig. 15 Panoramic radiograph after implant placement

fracture occurred during the whole period of the prostheses in situ. After 1 year, the mean MBL level was 0.37 $\pm 0.06 \mathrm{~mm}$, while the implant survival rate was $98.18 \%$ $(\mathrm{n}=54 / 55)$.

All implants obtained high primary stability, with insertion torque values greater than $35 \mathrm{Ncm}$, and were immediately loaded, except for one BLT, which was not loaded and resulted in failure at the stage of the definitive prosthesis.

In three patients, the debonding of the interim prostheses to 3 temporary abutments occurred after implant osseointegration at the removal of the prostheses at 1 year and was successfully resolved without any further complication.

\section{Discussion}

To the best of the authors' knowledge, this is the first study evaluating prospectively the use of digitally prefabricated interim prostheses without cast in computerassisted implant-supported full-arch rehabilitations.

All dental implants were placed with a s-CAIS protocol, raising full-thickness flaps to ensure the maximum keratinized mucosa preservation and using two surgical templates with the first guide mucosa- or toothsupported to achieve the maximum accuracy for implant positioning $[23,24]$. Implant quantity and position were decided on a patient-by-patient basis, considering bone availability, quality, anatomy, opposing dentition, and interocclusal recordings. In seven patients, bone quantity was enough for six implants to be placed, while in the remaining three patients the authors were limited by severe posterior mandibular atrophy and sinus anatomy. However, according to Polido et al. [25], there are no statistically significant differences in implant survival rates associated with the use of fewer than five implants when compared to five or more implants supporting a fixed dental prosthesis. While patients with four implants required computer-assisted implant placement due to the extremely difficult anatomy, subjects with six implants needed it for correct implant positioning for 


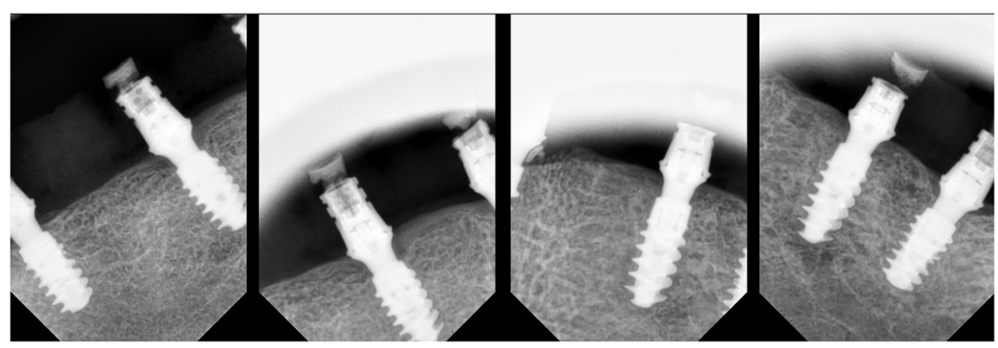

Fig. 16 Periapical X-rays at 1 year

future definitive prostheses delivery. The authors suggest that this last consideration should apply to all edentulous patients and can also be viewed as a procedure of a high-quality implant-restoration planning.

With a complete computer-assisted protocol of implant placement and immediate loading, it is possible to fabricate a restoration cemented on a Titanium base before surgery [26]. However, according to several studies on the accuracy of s-CAIS [5-7] and the direct experience of the authors of analyzing the data with Treatment Evaluation Tool, a 100\% accuracy in implant placement is not obtainable with s-CAIS. Thus, in full-arch rehabilitation, the provisional restorations cannot be cemented to abutments before surgery due to passivity concerns [27]. Therefore, in our study, interim prostheses were designed with wider access holes $(5 \mathrm{~mm}$ diameter) around titanium copings in order to connect them with the resin directly in the mouth. The accuracy of fit of the interim restoration between temporary copings and access holes depends on the accuracy of the surgical template and the accuracy of the s-CAIS. In all patients, interim prostheses allowed the insertion of titanium copings without the need of access hole enlargement or adaptation. However, patients with tilted implants and 17 or 30 SRA appeared to be more technique sensitive, with the tilted implants that should be placed in the exact planned position to let the corresponding SRA axis match with the axis of the access holes in the prosthesis. This was planned in the surgical software by engraving rotation markers on the surgical templates that were used as a reference when inserting the implant with the guided adapter. Different studies have demonstrated that patients use provisional

Table 1 Distribution of implants according to length and diameter

\begin{tabular}{lcccccc}
\hline Implant length & \multicolumn{6}{l}{ Implant diameters } \\
\cline { 2 - 6 } & $\mathbf{3 . 3}$ & $\mathbf{3 . 7 5}$ & $\mathbf{4 . 1}$ & $\mathbf{4 . 5}$ & $\mathbf{5 . 5}$ & $\mathbf{6 . 5}$ \\
\hline 6 & & & & & & 3 \\
8 & 2 & 10 & & 9 & 2 & \\
10 & & 2 & 3 & 2 & & \\
12 & & & & 19 & \\
\hline
\end{tabular}

prostheses for several months, until they receive the definitive rehabilitation $[28,29]$. Therefore, obtaining durable interim prostheses is mandatory in order to complete a successful rehabilitation and to allow a proper osseointegration for implants inserted. The evidence related to specific oral hygiene protocols for the implant-supported full arch is still limited: recently, Maeda et al. [30] reported that electric toothbrushes are more effective than manual toothbrushes for plaque removal in these patients. However, there are no data on the influence of the prosthetic design on cleanability.

In the present study, milled PMMA restorations proved to be durable enough during the long provisional phase. Hence, the superior flexural strength properties of PMMA considerably lowers the risk of fracture compared to conventional dentures converted in implantsupported interim prostheses [31]. Furthermore, a surface roughness below the plaque accumulation threshold has been reported for PMMA interim restorations in an in vitro study [32], therefore suggesting a lower risk of bacterial contamination for the prosthetic structure. The main limitation of this study is the small sample enrolled; furthermore, opposing dentition characteristics might have influenced the outcomes of this study, and hence, five patients had complete conventional dentures, generally associated with a lower incidence of prosthetic complications [33]. However, to the best of the authors' knowledge, the other studies in literature reporting data on prefabricated prostheses without cast present just case reports or description of clinical techniques [19, 20]; therefore, there are no studies to which our findings can be directly compared.

Future research should be orientated in conducting further randomized controlled clinical trials, with a

Table 2 Distribution of screw-retained abutments according to gingiva height and diameter

\begin{tabular}{|c|c|c|c|c|c|}
\hline \multirow[b]{2}{*}{ Gingiva height } & \multicolumn{5}{|c|}{ Diameters } \\
\hline & 1.5 & 2.5 & 3.5 & 4 & 4.5 \\
\hline $0^{\circ}$ & 22 & 18 & 6 & 2 & \\
\hline $17^{\circ}$ & & 1 & & & 2 \\
\hline $30^{\circ}$ & & 2 & 2 & & \\
\hline
\end{tabular}






Fig. 17 Interim prosthesis in situ at 1 year

larger sample, to evaluate the accuracy of full-arch interim prostheses fabricated with the digital technique without cast compared to conventional workflow.

\section{Conclusions}

Within the limitations of the present study, the authors concluded that digitally prefabricated provisional prostheses for full-arch immediate loading with s-CAIS could be a valid alternative treatment modality. Milled PMMA restorations proved to be durable enough during the long provisional phase, without major prosthetic complications.

\begin{abstract}
Abbreviations
s-CAIS: Static computer-aided implant surgery; PMMA: Polymethyl methacrylate; CAD/CAM: Computer-aided-design and computer-aidedmanufacturing; CBCT: Cone-beam computer tomography; STL: Standard Tessellation Language; DICOM: Digital Imaging and Communications in Medicine; SRA: Screw-retained abutments; SLActive: Sandblasted/long-grit/ acid-etched active; PTFE: Polytetrafluoroethylene; MBL: Marginal bone loss
\end{abstract}

\section{Acknowledgements}

The authors thank Aitor Alegria for CAD/CAM support.

\section{Authors' contributions}

NM: conceptualization, methodology, investigation, data curation, writing original draft, visualization. GP: validation, writing - review and editing, supervision. PP: formal analysis, investigation, writing - original draft. All authors read and approved the final manuscript.

\section{Funding}

The study was partially supported by the International Team for Implantology (ITI Research Grant No. 1237_2017)

\section{Availability of data and materials}

The datasets used and/or analyzed during the current study are available from the corresponding author on reasonable request.

\section{Declarations}

\section{Ethics approval and consent to participate}

All procedures performed in studies involving human participants were in accordance with the ethical standards of the institutional and/or national research committee and with the 1964 Helsinki declaration and its later amendments or comparable ethical standards. The study was approved by the Institution Review Board (IRB) of the Department of Oral and MaxilloFacial Sciences, at "Sapienza" University of Rome (Ref. 00021/2019)

\section{Consent for publication}

Each patient received detailed descriptions of the study protocol and all subjects signed the inform consent form and gave written approval to publish their individual data

\section{Competing interests}

The authors declare that they have no competing interests

\section{Author details}

${ }^{1}$ Department of Oral and Maxillo-Facial Sciences, "Sapienza" University of Rome, Via Caserta, 6, 00161 Rome, Italy. ${ }^{2}$ Oral Surgery Unit, Department of Oral and Maxillo-Facial Sciences, "Sapienza" University of Rome, Rome, Italy.

Received: 2 March 2021 Accepted: 16 June 2021

Published online: 06 September 2021

\section{References}

1. Papaspyridakos P, Chen CJ, Chuang SK, Weber HP. Implant loading protocols for edentulous patients with fixed prostheses: a systematic review and meta-analysis. Int J Oral Maxillofac Implants. 2014;29(Supplement):25670. https://doi.org/10.11607/jomi.2014suppl.g4.3.

2. Chen J, Cai M, Yang J, Aldhohrah T, Wang Y. Immediate versus early or conventional loading dental implants with fixed prostheses: a systematic review and meta-analysis of randomized controlled clinical trials. J Prosthet Dent. 2019;122(6):516-36. https://doi.org/10.1016/j.prosdent.2019.05.013.

3. Gallucci GO, Benic Gl, Eckert SE, Papaspyridakos P, Schimmel M, Schrott A, et al. Consensus statements and clinical recommendations for implant loading protocols. Int J Oral Maxillofac Implants. 2014;29(Supplement):28790. https://doi.org/10.11607/jomi.2013.g4.

4. Wismeijer D, Joda T, Flugge T, Fokas G, Tahmaseb A, Bechelli D, et al. Group 5 ITI Consensus Report: Digital technologies. Clin Oral Implants Res. 2018; 29(S16):436-42. https://doi.org/10.1111/clr.13309.

5. Monaco C, Arena A, Corsaletti L, Santomauro V, Venezia P, Cavalcanti R, et al. 2D/3D accuracies of implant position after guided surgery using different surgical protocols: a retrospective study. J Prosthodont Res 2020 https://doi.org/10.1016/j.jpor.2019.11.007 [Epub ahead of print.]

6. Derksen W, Wismeijer D, Flugge T, Hassan B, Tahmaseb A. The accuracy of computer-guided implant surgery with tooth-supported, digitally designed drill guides based on CBCT and intraoral scanning. A prospective cohort study. Clin Oral Implants Res. 2019;30(10):1005-15. https://doi.org/10.1111/ clr.13514.

7. Chmielewski K, Ryncarz W, Yuksel O, Goncalves P, Baek KW, Cok S, et al. Image analysis of immediate full-arch prosthetic rehabilitations guided by a digital workflow: assessment of the discrepancy between planning and execution. Int J Implant Dent. 2019;5(1):26. https://doi.org/10.1186/s40729019-0179-1.

8. Cappare P, Sannino G, Minoli M, Montemezzi P, Ferrini F. Conventional versus digital impressions for full arch screw-retained maxillary rehabilitations: a randomized clinical trial. Int J Environ Res Public Health. 2019;16(5):829. https://doi.org/10.3390/ijerph16050829.

9. Oh JH, An X, Jeong SM, Choi BH. A digital technique for fabricating an interim implant-supported fixed prosthesis immediately after implant placement in patients with complete edentulism. J Prosthet Dent. 2019; 121(1):26-31. https://doi.org/10.1016/j.prosdent.2018.03.030.

10. Santosa RE. Provisional restoration options in implant dentistry. Aust Dent J. 2007;52(3):234-42. https://doi.org/10.1111/j.1834-7819.2007.tb00494.x.

11. Lin WS, Eckert SE. Clinical performance of intentionally tilted implants versus axially positioned implants: A systematic review. Clin Oral Implants Res. 2018;29(S16):78-105. https://doi.org/10.1111/clr.13294.

12. Crespi R, Vinci R, Cappare P, Romanos GE, Gherlone E. A clinical study of edentulous patients rehabilitated according to the "all on four" immediate function protocol. Int J Oral Maxillofac Implants. 2012;27(2):428-34.

13. Vercruyssen M, Laleman I, Jacobs R, Quirynen M. Computer-supported implant planning and guided surgery: a narrative review. Clin Oral Implants Res. 2015;26:69-76. https://doi.org/10.1111/clr.12638.

14. De Vico G, Spinelli D, Bonino M, Schiavetti R, Pozzi A, Ottria L. Computerassisted virtual treatment planning combined with flapless surgery and immediate loading in the rehabilitation of partial edentulies. Oral implantol (Rome). 2012;5:3-10.

15. Aguirre BC, Chen $\mathrm{JH}$, Kontogiorgos ED, Murchison DF, Nagy WW. Flexural strength of denture base acrylic resins processed by conventional and CADCAM methods. J Prosthet Dent. 2020;123(4):641-6. https://doi.org/10.1016/j. prosdent.2019.03.010.

16. Sulaiman TA. Materials in digital dentistry-A review. J Esthet Restor Dent 2020;32(2):171-81. https://doi.org/10.1111/jerd.12566. 
17. Lanis A, Alvarez Del Canto O, Barriga P, Polido WD, Morton D. Computerguided implant surgery and full-arch immediate loading with prefabricatedmetal framework-provisional prosthesis created from a 3D printed model. J Esthet Restor Dent. 2019;31(3):199-208. https://doi.org/10.1111/jerd.12458.

18. Tahmaseb A, De Clerck R, Aartman I, Wismeijer D. Digital protocol for reference-based guided surgery and immediate loading: a prospective clinical study. Int J Oral Maxillofac Implants. 2012;27(5):1258-70.

19. Charette JR, Goldberg J, Harris BT, Morton D, Llop DR, Lin WS. Cone beam computed tomography imaging as a primary diagnostic tool for computerguided surgery and CAD-CAM interim removable and fixed dental prostheses. J Prosthet Dent. 2016;116(2):157-65. https://doi.org/10.1016/j. prosdent.2016.02.004.

20. Lewis RC, Harris BT, Sarno R, Morton D, Llop DR, Lin WS. Maxillary and mandibular immediately loaded implant-supported interim complete fixed dental prostheses on immediately placed dental implants with a digital approach: A clinical report. J Prosthet Dent. 2015;114(3):315-2. https://doi. org/10.1016/j.prosdent.2015.03.021.

21. Salvi GE, Bragger U. Mechanical and technical risks in implant therapy. Int J Oral Maxillofac Implants. 2009;24:69-85.

22. Corbella S, Del Fabbro M, Taschieri S, De Siena F, Francetti L. Clinical evaluation of an implant maintenance protocol for the prevention of periimplant diseases in patients treated with immediately loaded full-arch rehabilitations. Int J Dent Hyg. 2011;9(3):216-22. https://doi.org/10.1111/j.1 601-5037.2010.00489.x

23. Bornstein MM, Al-Nawas B, Kuchler U, Tahmaseb A. Consensus statements and recommended clinical procedures regarding contemporary surgical and radiographic techniques in implant dentistry. Int J Oral Maxillofac Implants. 2014;29(Supplement):78-82. https://doi.org/10.11607/jomi.2013.g1.

24. Raico Gallardo YN, da Silva-Olivio IRT, Mukai E, Morimoto S, Sesma N, Cordaro L. Accuracy comparison of guided surgery for dental implants according to the tissue of support: a systematic review and meta-analysis. Clin Oral Implants Res. 2017;28(5):602-12. https://doi.org/10.1111/clr.12841.

25. Daudt Polido W, Aghaloo T, Emmett TW, Taylor TD, Morton D. Number of implants placed for complete-arch fixed prostheses: a systematic review and meta-analysis. Clin Oral Implants Res. 2018;29(S16):154-83. https://doi. org/10.1111/clr.13312.

26. Arunyanak SP, Harris BT, Grant GT, Morton D, Lin WS. Digital approach to planning computer-guided surgery and immediate provisionalization in a partially edentulous patient. J Prosthet Dent. 2016;116(1):8-14. https://doi. org/10.1016/j.prosdent.2015.11.023.

27. Stapleton BM, Lin WS, Ntounis A, Harris BT, Morton D. Application of digital diagnostic impression, virtual planning, and computer-guided implant surgery for a CAD/CAM-fabricated, implant-supported fixed dental prosthesis: a clinical report. J Prosthet Dent. 2014;112(3):402-8. https://doi. org/10.1016/j.prosdent.2014.03.019.

28. Shen H, Di P, Luo J, Lin Y. Clinical assessment of implant-supported full-arch immediate prostheses over 6 months of function. Clin Implant Dent Relat Res. 2019;21(3):473-81. https://doi.org/10.1111/cid.12784

29. Agliardi E, Panigatti S, Clerico M, Villa C, Malo P. Immediate rehabilitation of the edentulous jaws with full fixed prostheses supported by four implants: interim results of a single cohort prospective study. Clin Oral Implants Res. 2010;21(5):459-65. https://doi.org/10.1111/j.1600-0501.2009.01852.x.

30. Maeda T, Mukaibo T, Masaki C, Thongpoung S, Tsuka S, Tamura A, et al. Efficacy of electric-powered cleaning instruments in edentulous patients with implant-supported full-arch fixed prostheses: a crossover design. Int J Implant Dent. 2019;26:7.

31. Keerthi S, Proussaefs P, Lozada J. Clinical and Laboratory Steps for Fabricating a Complete-Arch Fixed Prosthesis Using CAD/CAM. International J Periodontics Restorative Dent. 2015;35(4):473-80. https://doi.org/10.11607/ prd.2472.

32. Alp G, Johnston WM, Yilmaz B. Optical properties and surface roughness of prepolymerized poly(methyl methacrylate) denture base materials. J Prosthet Dent. 2019;121(2):347-52. https://doi.org/10.1016/j.prosdent.2018. 03.001.

33. Lopes A, Maló P, de Araújo NM, Sánchez-Fernández E, Gravito I. The NobelGuide ${ }^{\oplus}$ All-on-4 ${ }^{\oplus}$ treatment concept for rehabilitation of edentulous jaws: a retrospective report on the 7-years clinical and 5-years radiographic outcomes. Clin Implant Dent Relat Res. 2017;19(2):233-44. https://doi.org/1 $0.1111 /$ cid. 12456 .

\section{Publisher's Note}

Springer Nature remains neutral with regard to jurisdictional claims in published maps and institutional affiliations.

\section{Submit your manuscript to a SpringerOpen ${ }^{\circ}$ journal and benefit from:}

- Convenient online submission

- Rigorous peer review

- Open access: articles freely available online

- High visibility within the field

- Retaining the copyright to your article

Submit your next manuscript at $>$ springeropen.com 